\title{
Continuous distraction-induced delayed spinal cord injury on motor-evoked potentials and histological changes of spinal cord in a porcine model
}

\author{
J-Y Hong ${ }^{1}$, S-W Suh ${ }^{2}$, S-H Lee ${ }^{3}$, J-H Park ${ }^{1}$, S-Y Park ${ }^{4}$, IJ Rhyu ${ }^{5}$ and J-H Yang ${ }^{2}$
}

Study design: Experimental study.

Objectives: This study evaluated distraction-induced delayed spinal cord injury in a porcine model.

Setting: Department of Orthopedics, Korea University Guro Hospital, Seoul, Korea.

Methods: Global osteotomy of three columns was performed on the thirteenth thoracic vertebrae with 13 pigs. The osteotomized vertebrae were distracted to $57-103 \%$ of segmental vertebral height (SVH) length, which was less than the distraction length that induces prompt SCl. The vertebral height was maintained until the loss of motor-evoked potential (MEP) signals with continuous distraction. The distraction distance and the time at which $\mathrm{SCl}$ occurred were measured, and distraction was then released to observe MEP recovery patterns.

Results: We found delayed $\mathrm{SCl}$ in 8 of the 12 pigs, with a mean $20.9 \mathrm{~mm}$ (range 19-25 mm) and 10.7 min (range 8-12 min) of continuous spinal distraction, which was equivalent to $74.3 \%$ (68-84\%) of SVH and $3.63 \%(3.42-4.31 \%)$ of thoracolumbar spinal length. A continuous $74.3 \% \mathrm{SVH}$ distraction over an average of 10.7 min caused a delayed $\mathrm{SCl}$, which was indicated by mild histologic changes in the spinal cord. Recovery patterns from SCl after distraction release were compatible with the degree of histological change; however, these patterns differed from the previously investigated prompt type of SCl.

Conclusion: Late onset injury due to continuous spinal distraction, which is comparable to iatrogenic $\mathrm{SCl}$ in spinal correction surgery, is important for understanding the impact of corrective surgery.

Spinal Cord (2016) 54, 649-655; doi:10.1038/sc.2015.231; published online 19 January 2016

\section{INTRODUCTION}

Because of improvements in spinal surgery techniques, severe spinal deformity corrections have recently become feasible. ${ }^{1-3}$ In addition, intraoperative neuromonitoring tools, including somatosensoryevoked potentials and transcranial motor-evoked potentials (TcMEPs), are employed to prevent spinal cord injury (SCI). These monitoring tools have been applied to identify early stage SCI and to minimize potential complications. ${ }^{4-10}$ However, regardless of the high reliability associated with spinal cord operations, iatrogenic SCI still occurs during surgeries. Moreover, in corrective spinal deformity surgery, the spinal column and the spinal cord are continuously distracted for a specific amount of time, which can induce SCI. ${ }^{2,3,7,11-13}$ Therefore, appropriate animal SCI models can be used to study and acquire techniques to prevent iatrogenic SCI during surgery. Many animal models have been used to study traumatic SCI; however, these models differ with respect to iatrogenic SCI during surgery, and they also differ from human surgeries. ${ }^{14-23}$ We hypothesized that it would be most instructive for surgeons to examine the effects of SCI in a large animal, induced by durational parallel spinal distraction over significant time intervals. The purpose of this study was to examine distraction-induced late-onset SCI (delayed SCI) with Tc-MEP and evaluate a wake-up test and corresponding histology consequences in a large animal model.

\section{MATERIALS AND METHODS}

Subjects

The study was performed in 13 young farm pigs (Landrace and Yorkshire mixed, Korea) after obtaining approval from the Institutional Animal Care and Use Committee. The average age and weight of the animals were 3.2 months (3-4 months) and $52.3 \mathrm{~kg}(45-55 \mathrm{~kg})$, respectively. All the experiments were performed at the Biomedical Animal Research Center under the supervision of veterinarians.

\section{Preoperative preparation and anesthesia}

To anesthetize the animals, Zoletil (Virbac, Carros, France) $\left(4.4 \mathrm{mg} \mathrm{kg}^{-1}\right)$ was administered intramuscularly and was followed by continuous intravenous anesthesia with Propofol (Astra-Zeneca, Luton, UK) (12-20 $\mathrm{mg} \mathrm{kg}^{-1}$ ). Subsequently, each pig was intubated with an endotracheal tube and maintained on intravenous Propofol without a muscle relaxant in order to minimize false signals during MEP monitoring under electrocardiography and pulse oximetry monitoring. ${ }^{24}$

${ }^{1}$ Division of Spinal Surgery, Department of Orthopedics, Korea University Ansan Hospital, Ansan, Korea; ${ }^{2}$ Department of Orthopedics, Scoliosis Research Institute, Korea University Guro Hospital, Guro, Korea; ${ }^{3}$ Department of Orthopedic Surgery, Spine Center, Kyung Hee University Hospital at Gangdong, School of Medicine, Seoul, Korea; ${ }^{4}$ Department of Orthopedics, Spine Center, Korea University Anam Hospital, Anam, Korea and ${ }^{5}$ Department of Anatomy, Korea University school of medicine, Seoul, Korea

Correspondence: Professor S-W Suh, Department of Orthopedics, Scoliosis Research Institute, Korea University Guro Hospital, 80 Guro-Dong, Guro-Gu, Seoul 152-703, South Korea, Guro 2-dong, Guro-gu, Seoul 152-703, Korea.

E-mail: spine@korea.ac.kr

Received 25 April 2015; revised 13 August 2015; accepted 1 September 2015; published online 19 January 2016 

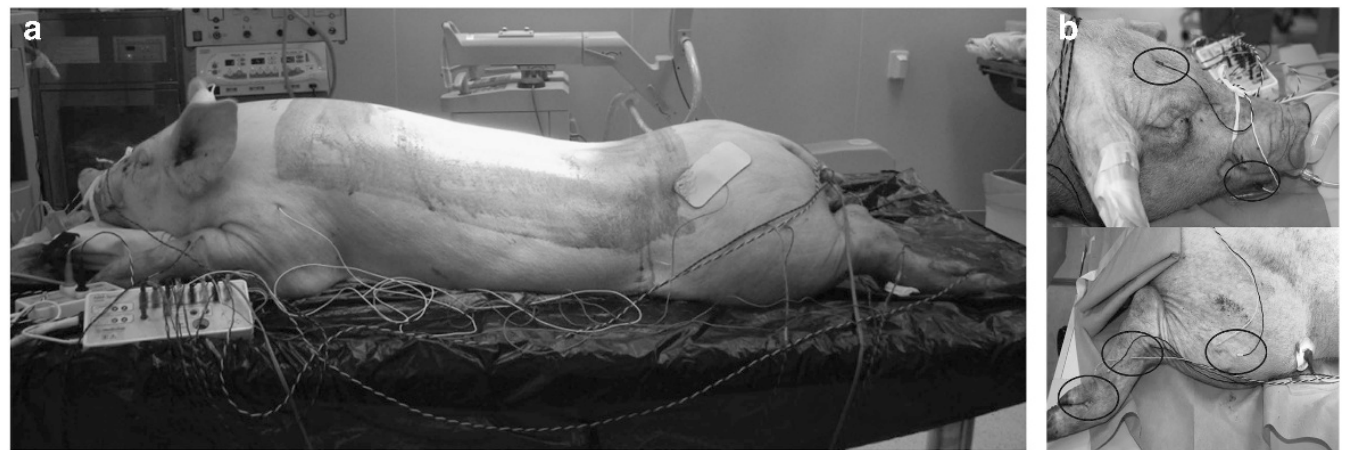

Figure 1 (a) A Tc-MEP (Nims Spine, Medtronic, USA) monitoring system was applied. (b) Needle electrode leads were bilaterally inserted at $\sim 2 \mathrm{~cm}$ intervals in the quadriceps, gastrocnemius and abductor hallucis muscles.
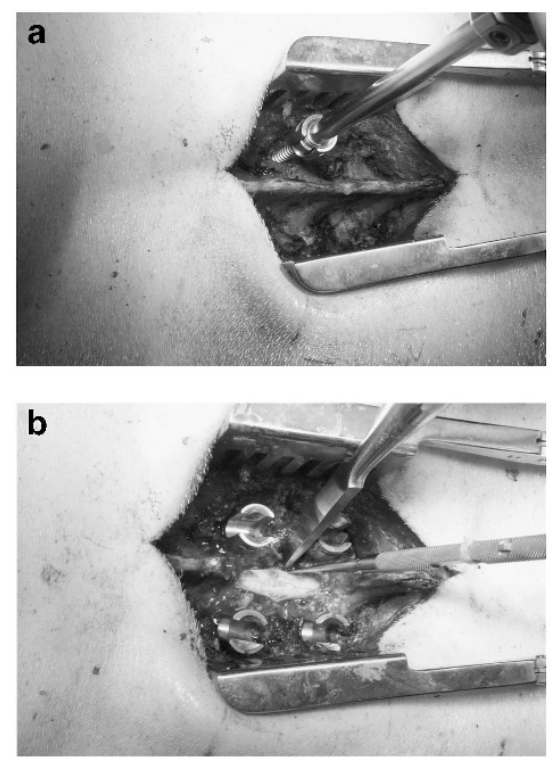

C
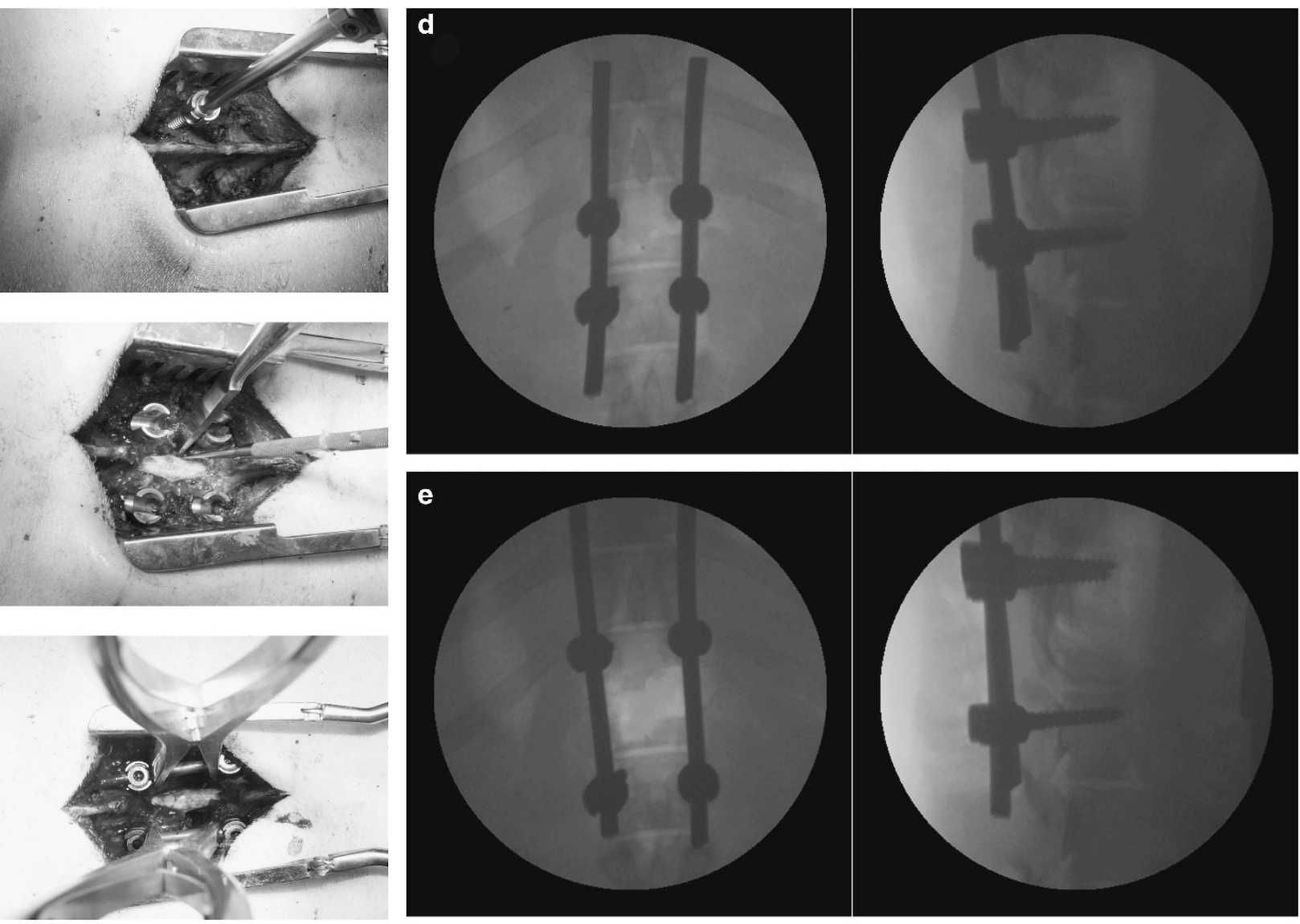

Figure 2 (a) A pedicle screw was inserted into the pedicle. (b) Global osteotomy of the anterior column was performed. (c) A bilateral rod was inserted in the screws, and gradual distraction was applied. (d, e) Distraction was confirmed under the image intensifier by observing parallel widening of the gap between vertebrae.

\section{Neuromonitoring positioning and preparation}

After the animals were anesthetized, several anatomical parameters were measured on each pig. The details of the measurements performed are as follows:

Thoracolumbar spinal length (TLSL) was measured as the distance from the upper end plate of the first thoracic to the upper end plate of the first sacral vertebrae.

Vertebral height $(\mathrm{VH})$ was measured as the distance from the upper end plate to the lower end plate of the 13 thoracic vertebra.

Disc height (DH) was measured as the mean height of the T13-L1 disc space.

SVH was measured as the sum of $\mathrm{VH}$ and $\mathrm{DH}$ at the osteotomy level.
A Tc-MEP (Nims Spine System, Medtronic, USA) monitoring system was used for this study. A neurophysiologist operated the Tc-MEP monitoring system and provided assistance in reading and analyzing the neuromonitoring signals. Six needle electrode leads were bilaterally inserted at $\sim 2 \mathrm{~cm}$ intervals into the quadriceps, gastrocnemius and abductor hallucis muscles. Two needle electrode leads were inserted in the biceps on both upper extremities as references (Figures 1a and b). The amplitude of the peak wave was identified as the baseline when the peak wave signal appeared on all channels at repeated stimulation times. SCI was inferred when there was a $>80 \%$ decrease in the amplitudes in the six leads (lower extremity) from the baseline Tc-MEP amplitudes or the amplitude completely disappeared while the upper extremity 
signal was preserved. ${ }^{4-10,25-28}$ Among the 13 total pigs, 1 showed immediate MEP signal loss and reduced blood pressure after vertebral osteotomy; this pig was excluded from the study. Therefore, the final study included 12 animals.

\section{Surgical procedure}

A 15-18-cm-long vertical incision was made in the middle of the back and centered at T13-L1. Dissection was performed with coagulation cautery throughout. The Tc-MEP signal was recorded at every major time point (dissection, screw insertion, osteotomy, distraction and so on). After dissection, the T13 and L1 pedicles were confirmed with an image intensifier, and passage was created using a pathfinder. A $4 \times 30$-mm-sized pedicle screw was inserted into the pedicle, and a total laminectomy of T13 was performed using a 2-mm Karrison punch. Global osteotomy of the anterior column was performed just below the T13 pedicle with a 10-mm osteotome, while the cord was protected with a root retractor (Figures 2a and b). After complete osteotomy of the T13 vertebrae, a bilateral rod was inserted through the screws, and the initial distance between the T13 and L1 pedicles was measured. Complete osteotomy was confirmed under the image intensifier by observing parallel widening (Figures 2c-e). Subsequently, Tc-MEP monitoring values were compared with baseline amplitude, and gradual distraction was applied.

\section{Continuous spinal column distraction over time}

We classified the types of SCI into two categories. 'Prompt SCI' was defined as early onset cord injury with immediate loss of MEP signals after significant spinal column distraction. ${ }^{28}$ 'Delayed SCI' was defined as late-onset SCI without immediate loss of MEP signals after spinal column distraction that showed delayed MEP signal loss with continuous distraction. Initially, we performed significant distraction in two pigs $(>3.6 \%$ of the TLSL, which induced prompt SCI and was comparable to that observed in a previous experiment. ${ }^{28}$ To avoid prompt SCI, spinal distraction was performed with $<3.6 \%$ of TLSL $(<96 \%$ of the SVH) with continuous spinal column distraction until MEP loss was observed in ten pigs.

After measuring the initial length, gradual distraction was performed to investigate the delayed SCI. Tc-MEP signals were recorded at every $2 \mathrm{~mm}$ of distraction with resting periods of $30 \mathrm{~s}$ until the distraction reached the final length (57-84\% of SVH), and the distraction amount was measured using vernier calipers after the rod was fixed. The rod fixation was maintained with continuous spinal column distraction until the MEP signals disappeared, and maintenance time was measured at $30 \mathrm{~s}$ intervals. The SCI was recorded when the Tc-MEP signals in all of the leads disappeared or decreased to $<80 \%$ of the baseline amplitude. ${ }^{5,6}$ We ended the distraction if there was no indication of SCI on neuromonitoring through $30 \mathrm{~min}$, despite the continuous distraction.

The distraction was released to the original position after $90 \mathrm{~s}$, and MEP signals were measured to monitor signs of recovery after $10 \mathrm{~min}$, upon development of delayed SCI on MEP signals. Recovery patterns in MEP signals were classified into three types:

(1) complete recovery: return of signal in all leads upon Tc-MEP monitoring;

(2) incomplete recovery: return of signal in some but not all leads;

(3) no recovery: no return of signal in any of the leads.

\section{Wake-up test}

We performed the wake-up test to rule out false-negative or -positive MEP signals. At the end of the experiment, the pig was awakened from anesthesia. Lower extremity movement and sensory response by mechanical stimulation were observed at $30 \mathrm{~min}$ after osteotomy stabilization and at 2 days after the experiment. $^{28}$

Sensory response. Mechanical stimulation was applied using a Sensory Evaluator Kit (von Frey, Semmes-Weinstein monofilaments, USA) that was inserted vertically into the dorsal hind foot. A brisk withdrawal or foot flinching was considered to be a positive response.

Motor response. Muscle strength was divided into three grades according to ambulation status: independent walking/standing with assistance/inability to stand despite assistance.

\section{Histological examination}

Spinal cord samples were collected before killing, and the specimens were fixed in buffered formalin. A serial longitudinal section was made around the middle of the specimen, and a serial cross-section was made at the mid-portion of the swollen area, each was made caudally and cephalad with $1 \mathrm{~mm}$ intervals. Subsequently, hematoxylin and eosin staining was used to evaluate morphologic and structural changes of white and gray matter, as well as nerve sheath and general spinal cord conditions such as hemorrhage and inflammation.

\section{Statistical analysis and data interpretation}

Each individual distraction length and time on delayed SCI was calculated and analyzed with the TLSL, VH, DH, SVH, distraction distance (DD)/SVH and $\mathrm{DD} / \mathrm{TLSL}$ with correlation analysis. In addition, these parameters on delayed SCI were analyzed with respect to the changes in Tc-MEP signal, wake-up test and histologic findings, when it was lost or recovered. Spearman's correlation analysis and the Mann-Whitney $U$-test were used for the study. All the analyses were performed using SPSS version 13 (SPSS, Chicago, IL, USA). A P-value $\geqslant 0.05$ was considered statistically significant.

\section{RESULTS}

The average age, weight, TLSL, $\mathrm{VH}, \mathrm{DH}, \mathrm{SVH}$ and intraoperative estimated blood loss are described in Table 1. The mean TLSL, $\mathrm{VH}, \mathrm{DH}, \mathrm{SVH}$ and estimated blood loss were $573.8 \pm 13.8 \mathrm{~mm}$,

Table 1 Dermographs of the subjects

\begin{tabular}{|c|c|c|c|c|c|c|c|}
\hline No & Age (month) & $W t(\mathrm{~kg})$ & $T L S L(m m)$ & $V H(m m)$ & $D H(m m)$ & $S V H(m m)$ & $E B L(m l)$ \\
\hline 1 & 3 & 45 & 570 & 23.2 & 2.9 & 26.1 & 550 \\
\hline 2 & 3 & 54 & 560 & 22.8 & 2.9 & 25.7 & 440 \\
\hline 3 & 3 & 55 & 585 & 26.4 & 3.1 & 29.5 & 720 \\
\hline 4 & 3 & 52 & 560 & 24.5 & 3.2 & 27.7 & 380 \\
\hline 5 & 4 & 55 & 590 & 25.5 & 2.9 & 28.4 & 500 \\
\hline 6 & 3 & 52 & 575 & 24.1 & 3.2 & 27.3 & 490 \\
\hline 7 & 3.5 & 55 & 560 & 24.8 & 2.9 & 27.7 & 500 \\
\hline 8 & 3 & 54 & 590 & 23.9 & 3.4 & 27.3 & 520 \\
\hline 9 & 3 & 52 & 575 & 25.4 & 3.0 & 28.4 & 610 \\
\hline 10 & 3 & 52 & 580 & 26.5 & 3.3 & 29.8 & 480 \\
\hline 11 & 3.5 & 51 & 550 & 25.1 & 3.1 & 28.2 & 610 \\
\hline 12 & 3 & 53 & 590 & 24.9 & 3.3 & 28.2 & 590 \\
\hline Mean & $3.2 \pm 0.3$ & $52.5 \pm 2.7$ & $573.8 \pm 13.8$ & $24.8 \pm 1.1$ & $3.1 \pm 0.2$ & $27.9 \pm 1.2$ & $532.5 \pm 90.2$ \\
\hline
\end{tabular}

Abbreviations: $\mathrm{DH}$, disc height; EBL, estimated blood loss; SVH, segmental vertebral height; TLSL, thoracolumbar spinal length; VH, vertebral height; Wt, body weight. 
$24.8 \pm 1.1 \mathrm{~mm}, \quad 3.1 \pm 0.2 \mathrm{~mm}, \quad 27.9 \pm 1.2 \mathrm{~mm}$ and $532.5 \pm 90.2 \mathrm{ml}$, respectively. We performed a correlation analysis to determine the relationships between these parameters and SCI. The average length of spinal distraction resulting in delayed SCI was $20.9 \mathrm{~mm}(19-25 \mathrm{~mm})$, and, the mean DD with delayed SCI was significantly correlated with $\mathrm{DD} / \mathrm{SVH}$ and DD/TLSL $(r=0.794 ; P=0.019, r=0.952 ; P=0.001)$, but TLSL, VH, DH, SVH and estimated blood loss were not correlated $(P>0.05)$, according to Spearman's correlation test. Consequently, we analyzed the results according to DD/SVH and DD/TLSL values.

\section{MEP spinal cord functional assessment with a wake-up test and histology findings}

(1) Delayed SCI patterns based on MEP signals with continuous distraction. Table 2 provides the distraction lengths (DD) of the T13 vertebral bodies with MEP signal changes. We induced prompt SCI in two pigs as controls, and the average length of spinal column distraction resulting in prompt SCI was $28 \mathrm{~mm}(\mathrm{DD}=27-29 \mathrm{~mm}$; pigs 11 and 12), which was comparable to $99.5 \%$ of $\mathrm{SVH}$ $(\mathrm{DD} / \mathrm{SVH}=96-103 \%)$ and $4.92 \%$ of VTL $(\mathrm{DD} / \mathrm{TLSL}=4.91-4.92 \%)$. We were unable to induce SCI in two pigs with a smaller distraction length, and the average length that failed to induce SCI (MEP signals were maintained for $30 \mathrm{~min}$ of distraction) was $15.3 \mathrm{~mm}$ $(\mathrm{DD}=15-15.5 \mathrm{~mm}$; pigs 1 and 2 ), which was comparable to $58.5 \%$ of the SVH $(\mathrm{DD} / \mathrm{SVH}=57-60 \%)$ and $2.70 \%$ of VTL (DD/TLSL $=2.63-2.77 \%)$. Consequently, we found delayed SCI based on MEP signals in eight pigs, and the average length and time of continuous spinal column distraction were $20.9 \mathrm{~mm}$ (19-25 mm; pigs 3-10) with a mean of $10.7 \mathrm{~min}(8.5-12 \mathrm{~min})$ until MEP loss; this was comparable to $74.3 \%$ of $\mathrm{SVH}(\mathrm{DD} / \mathrm{SVH}=68-84 \%)$ and $3.63 \%$ of TLSL (DD/TLSL $=3.42-4.31 \%$ ). In the delayed SCI group, abrupt MEP signal bursting greater than twice the baseline was observed in six pigs (pigs 3, 4, 6, 7, 9 and 10) with a mean of 7.7 min of distraction (6-9 min). In addition, there was significant MEP signal loss several minutes after abrupt MEP signal bursting.

(2) Recovery patterns based on MEP signals and a wake-up test. Table 3 provides the recovery patterns after release based on MEP signals and wake-up test results. In the delayed MEP signal loss group, there were three pigs with complete MEP recovery and five pigs that did not

Table 2 Changes in MEP signals with continuous distraction

\begin{tabular}{|c|c|c|c|c|c|c|}
\hline \multirow[t]{2}{*}{ No } & \multirow[t]{2}{*}{$D D(m m)$} & \multirow[t]{2}{*}{$\begin{array}{c}D D / S V H \\
(\%)\end{array}$} & \multirow[t]{2}{*}{$\begin{array}{c}D D / T L S L \\
(\%)\end{array}$} & \multicolumn{2}{|c|}{$\begin{array}{c}\text { Distraction period } \\
\text { with MEP changes } \\
\text { (minutes) }\end{array}$} & \multirow[t]{2}{*}{ SCl type } \\
\hline & & & & MEP burst & MEP loss & \\
\hline 1 & 15 & 57 & 2.63 & - & - & No \\
\hline 2 & 15.5 & 60 & 2.77 & - & - & No \\
\hline 3 & 20 & 68 & 3.42 & 7 & 8.5 & Delayed \\
\hline 4 & 19 & 69 & 3.39 & 7 & 11 & Delayed \\
\hline 5 & 19.5 & 69 & 3.31 & - & 9 & Delayed \\
\hline 6 & 19 & 70 & 3.30 & 6 & 12 & Delayed \\
\hline 7 & 21 & 76 & 3.75 & 9 & 11 & Delayed \\
\hline 8 & 21 & 77 & 3.56 & - & 12 & Delayed \\
\hline 9 & 23 & 81 & 4.00 & 8 & 10 & Delayed \\
\hline 10 & 25 & 84 & 4.31 & 9 & 12 & Delayed \\
\hline 11 & 27 & 96 & 4.91 & - & 0 & Prompt \\
\hline 12 & 29 & 103 & 4.92 & - & 0 & Prompt \\
\hline
\end{tabular}

Abbreviations: DD, distraction length; MEP, motor-evoked potential; $\mathrm{SCl}$, spinal cord injury; $\mathrm{SVH}$, segmental vertebral height; TLSL, thoracolumbar spinal length. completely recover. Five pigs with a distraction length $>70 \%$ of SVH (70-84\%; mean DD =21.8 mm; pigs 6, 7, 8, 9 and 10) showed MEP recovery deficits. Animals with incomplete MEP recovery showed partial positive responses to sensory and motor tests, indicating real SCI, whereas three pigs with complete recovery showed no deficits in motor or sensory function. In comparison, no cases in the prompt SCL group (pigs 11 and 12) showed recovery of MEP signals with paralysis on wake-up test.

(3) Histologic changes after delayed SCI. Table 3 provides the histologic changes after delayed SCI. The three completely recovered pigs did not show any histological changes, whereas five of the incomplete recovery subjects showed mild changes in the spinal cord with hemorrhagic infiltrations but no significant structural changes. There were no definitive axonal damage features, such as axotomy, in this group, although the neural connective tissue alignments were broken, with numerous vacuoles and hemorrhagic infiltrations between the neural cells in the white matter (Figures $3 \mathrm{a}$ and $\mathrm{b}$ ). However, the prompt SCI group (pigs 11 and 12) showed significant histologic changes with structural disruption of the gray matter with axotomy (Figures 3c-e).

\section{Differences in parameters according to MEP, wake-up test and histology findings}

We compared the parameter differences in the delayed SCI group (subjects 3-10) with regard to MEP burst pattern, MEP recovery, wake-up test results and histologic changes (Table 4). There were no differences in the parameters in the MEP burst group and the nonburst group $(P>0.05)$. However, there were differences in the complete and incomplete MEP and wake-up recovering groups in the DD/SVH $(P=0.036)$. Finally, the mild histologic change group and the group without histologic changes showed the differences in $\mathrm{DD} / \mathrm{SVH}(P=0.036)$. The $\mathrm{DD} / \mathrm{SVH}$ values were higher in the incomplete MEP and wake-up recovery group, as well as in the mild histologic change group (77.4 vs $68.4 \%$ ). However, there were no other significant differences when other parameters were compared $(P>0.05)$.

\section{Table 3 Recovery patterns on MEP, wake-up test and histologic results}

\begin{tabular}{|c|c|c|c|c|c|c|}
\hline \multirow[t]{2}{*}{ No } & \multirow[t]{2}{*}{$D D(m m)$} & \multirow{2}{*}{$\begin{array}{c}D D / S V H \\
(\%)\end{array}$} & \multirow{2}{*}{$\begin{array}{c}D D / T L S L \\
(\%)\end{array}$} & \multicolumn{2}{|c|}{ Recovery pattern } & \multirow[t]{2}{*}{ Histology } \\
\hline & & & & $\begin{array}{c}\text { MEP } \\
\text { signals }\end{array}$ & $\begin{array}{c}\text { Wake up } \\
\text { (M/S) }\end{array}$ & \\
\hline 1 & 15 & 57 & 2.63 & - & - & No \\
\hline 2 & 15.5 & 60 & 2.77 & - & - & No \\
\hline 3 & 20 & 68 & 3.42 & Comp & Comp/comp & No \\
\hline 4 & 19 & 69 & 3.39 & Comp & Comp/comp & No \\
\hline 5 & 19.5 & 69 & 3.31 & Comp & Comp/comp & No \\
\hline 6 & 19 & 70 & 3.30 & Incomp & $\begin{array}{l}\text { Incomp/ } \\
\text { incomp }\end{array}$ & Mild \\
\hline 7 & 21 & 76 & 3.75 & Incomp & Incomp/no & Mild \\
\hline 8 & 21 & 77 & 3.56 & Incomp & Incomp/no & Mild \\
\hline 9 & 23 & 81 & 4.00 & No & Incomp/no & Mild \\
\hline 10 & 25 & 84 & 4.31 & Incomp & No/incomp & Mild \\
\hline 11 & 27 & 96 & 4.91 & No & No/no & Sig \\
\hline 12 & 29 & 103 & 4.92 & No & No/no & Sig \\
\hline
\end{tabular}

Abbreviations: Comp, complete recovery; DD, distraction length; Incomp, incomplete recovery; M, motor recovery; Mild, mild change; S, sensory recovery; Sig, significant change; SVH, segmental vertebral height; TLSL, thoracolumbar spinal length. 

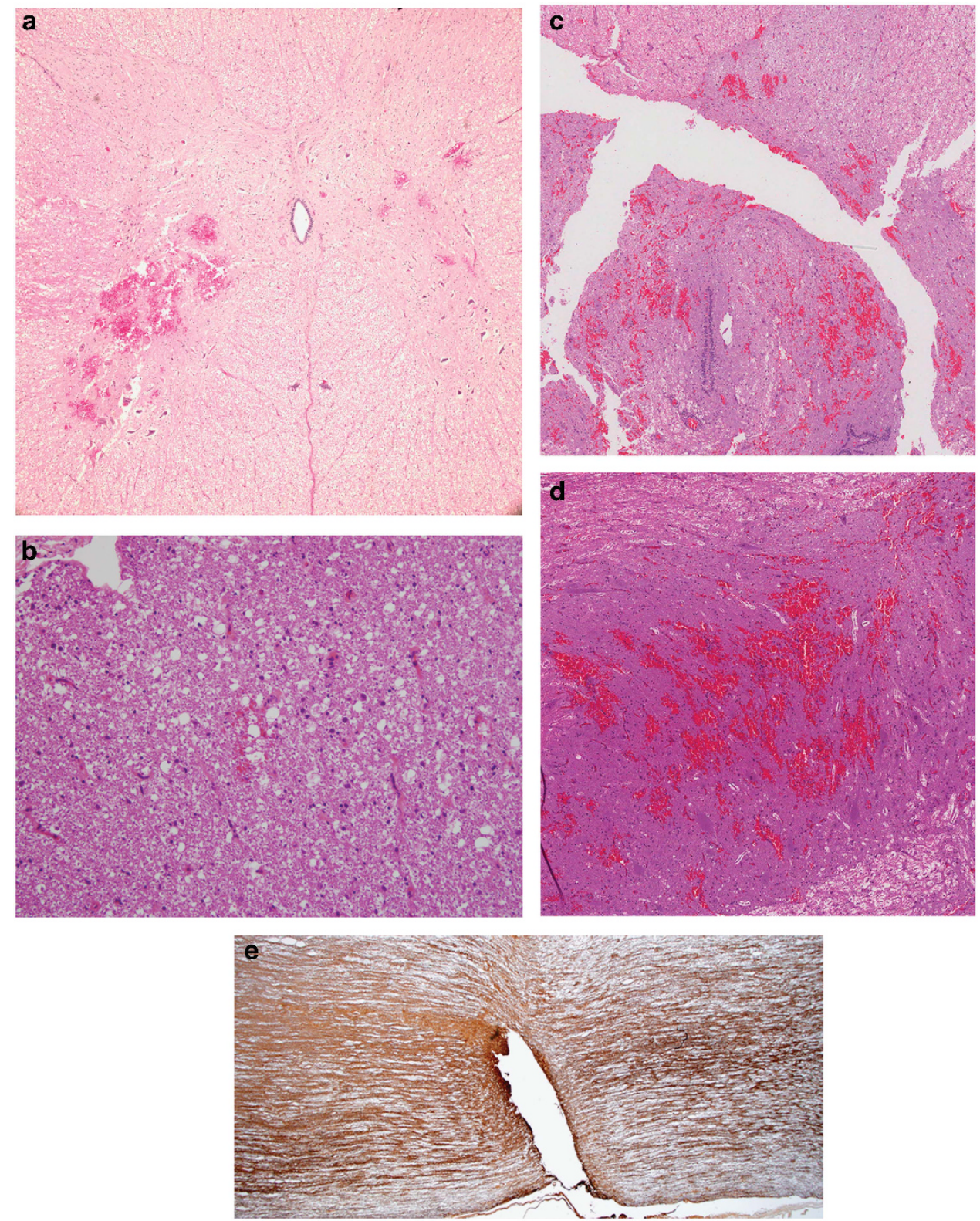

Figure 3 (a, b) Mild pathologic changes did not exhibit definitive features of axonal damage, but the neural connective tissue alignments were disrupted with numerous vacuoles and hemorrhagic infiltrations between the neural cells (hematoxylin and eosin, cross-section $\times 40$, Iongitudinal section $\times 100$ ). (c-e) Significant histologic changes are indicated by structural disruption of the gray matter with axotomy and massive hemorrhagic infiltrations between the neural cells (hematoxylin and eosin, cross-section $\times 40$, longitudinal section $\times 100$ ).

\section{DISCUSSION}

The distraction force applied to the spinal cord during correction procedures for spinal deformity may be significant, and there is always a potential risk of SCI. ${ }^{10-13}$ Currently, surgeons debate about the optimal length and time of distraction to avoid paralysis, and detailed animal experimental studies are required to investigate distraction SCI. $7,10,13,15,18,22$ Appropriate experimental models of distracting or compressing the spinal cord using global corpectomy have been identified in other studies. ${ }^{28,29}$ In our previous study, we determined the mean length of distraction to induce 'prompt SCI' in 16 pigs, which was comparable to $3.6 \%$ of the TLSL with significant histologic changes. ${ }^{28}$ However, delayed SCI with continuous cord distraction with a smaller distraction length can cause paralysis, which is comparable to situations that can occur during surgery. Therefore, we worked to establish another pattern of SCI based on delayed SCI with continuous distraction. Consequently, our results indicate that a mean of $20.9 \mathrm{~mm}$ and $10.7 \mathrm{~min}$ of continuous distraction, comparable to $74.3 \%$ of SVH, caused delayed SCI on MEP signals in a swine model. This is the first report, to our knowledge, that discusses delayed SCI in swine with MEP, wake-up results and histologic testing.

In this study, MEP signals were preserved immediately after distraction but disappeared after prolonged distraction in the delayed SCI group. The correlation analysis indicated that the DD that is comparable to SVH was significantly related to delayed SCI and affected the various MEP recovery or wake-up test results. We assumed that damage to the spinal cord may accumulate through 
Table 4 Differences of parameters according to $\mathrm{SCl}$ patterns

\begin{tabular}{|c|c|c|c|c|}
\hline & MEP burst & MEP recovery & Wake-up test & $\begin{array}{c}\text { Histologic } \\
\text { change }\end{array}$ \\
\hline & $\begin{array}{l}\text { Exist vs } \\
\text { non-exist }\end{array}$ & $\begin{array}{c}\text { Complete vs } \\
\text { incomplete }\end{array}$ & $\begin{array}{l}\text { Complete vs } \\
\text { incomplete }\end{array}$ & $\begin{array}{c}\text { No vs mild } \\
\text { change }\end{array}$ \\
\hline Age & $3.1 / 3.5$ & $3.3 / 3.1$ & $3.3 / 3.1$ & $3.3 / 3.1$ \\
\hline$P$-value & 0.429 & 0.786 & 0.786 & 0.786 \\
\hline Wt & $53.0 / 54.5$ & $54.0 / 53.0$ & $54.0 / 53.0$ & $54.0 / 53.0$ \\
\hline$P$-value & 0.429 & 0.393 & 0.393 & 0.393 \\
\hline EBL & $530 / 510$ & $533 / 520$ & $533 / 520$ & $533 / 520$ \\
\hline$P$-value & 0.643 & 1.000 & 1.000 & 1.000 \\
\hline DH & $3.1 / 3.2$ & $3.1 / 3.2$ & $3.1 / 3.2$ & $3.1 / 3.2$ \\
\hline$P$-value & 0.857 & 0.571 & 0.571 & 0.571 \\
\hline VH & $25.3 / 24.7$ & $25.5 / 24.9$ & $25.5 / 24.9$ & $25.5 / 24.9$ \\
\hline$P$-value & 0.643 & 0.571 & 0.571 & 0.571 \\
\hline TLSL & $573 / 590$ & $578 / 576$ & $578 / 576$ & $578 / 576$ \\
\hline$P$-value & 0.071 & 0.786 & 0.786 & 0.786 \\
\hline SVH & $28.4 / 27.9$ & $28.5 / 28.1$ & $28.5 / 28.1$ & $28.5 / 28.1$ \\
\hline$P$-value & 0.643 & 0.571 & 0.571 & 0.571 \\
\hline DD & $21.2 / 20.3$ & $19.5 / 21.8$ & $19.5 / 21.8$ & $19.5 / 21.8$ \\
\hline$P$-value & 0.857 & 0.143 & 0.143 & 0.143 \\
\hline $\mathrm{DD} / \mathrm{SVH}$ & $74.7 / 73.0$ & $68.7 / 77.6$ & $68.7 / 77.6$ & $68.7 / 77.6$ \\
\hline$P$-value & 0.857 & $* 0.036$ & $* 0.036$ & $* 0.036$ \\
\hline DD/TLSL & $3.70 / 3.44$ & $3.37 / 3.78$ & $3.37 / 3.78$ & $3.37 / 3.78$ \\
\hline$P$-value & 0.643 & 0.250 & 0.250 & 0.250 \\
\hline Time to SCl & $10.8 / 10.5$ & $9.5 / 11.4$ & $9.5 / 11.4$ & $9.5 / 11.4$ \\
\hline$P$-value & 1.000 & 0.071 & 0.071 & 0.071 \\
\hline
\end{tabular}

Abbreviations: DD, distraction length; $\mathrm{DH}$, disc height; $\mathrm{EBL}$, estimated blood loss; $\mathrm{SCl}$, spinal cord injury; SVH, segmental vertebral height; TLSL, thoracolumbar spinal length; $\mathrm{VH}$, vertebral height; Wt, body weight.

The Mann-Whitney test was used to determine the significant differences of parameters. There exist significant differences of DD/SVH value in different MEP, wake up and histologic result groups with delayed $\mathrm{SCl}$.

* and bold values indicate $P<0.05$

the distraction period in 'delayed SCI' and may induce spinal cord dysfunction. In addition, persistent spinal column distraction may worsen or increase changes in the cord, which can lead to irreversible damage. ${ }^{16,17,22,23,30}$ In regard to the MEP signal recovery patterns and wake-up test results, three pigs with smaller distraction lengths showed complete recovery, whereas five pigs with larger distraction lengths showed incomplete or no recovery in a similar distraction time. Therefore, this indicates that a distraction $>70 \%$ of SVH may induce irreversible injury, which correlates with an MEP recovery signal deficit and a wake-up test after release. Specifically, this study observed an MEP burst in six pigs (abrupt increase in MEP amplitude), which was consequently connected to the delayed MEP loss. In our opinion, the continuing distraction of the spinal column leads to physiological changes that induce MEP bursts. We assume that 'MEP burst' may be a sign of delayed SCI in swine distraction model.

In this study, histologic examination of the spinal cord with 'prompt SCI' showed significant neuronal damage that ultimately led to axonal cutting and intradural and epidural hematoma formation that was comparable to that in a previous study. ${ }^{28}$ However, specimens of 'delayed SCI' showed mild hemorrhage without evident structural changes, despite the deficits on MEP recovery and wake-up test results. Neuronal connective tissue loosening with vacuoles and a small amount of white mater hemorrhaging was observed in the delayed SCI group, which was different from the histologic changes with prompt SCI. ${ }^{20,28,31}$ It appears that delayed SCI can be caused by accumulation of damage with continuous distraction without evident structural changes. Although this pattern of SCI can be confused with 'neuropraxia' or 'false-positive MEP signals,' it was confirmed with incomplete recovery on a wake-up test, which indicates actual SCI. In addition, the results indicate that damage to the spinal cord is not confined to immediately after the initial injury but continues during the distraction period. Secondary injury processes may progress with prolonged distraction that can induce hemorrhage and macrophage infiltration. In addition, accumulated cord damage could be irreversible regardless of minimal histologic changes. The observed results emphasize the importance of distraction time in delayed SCI in a swine model.

Our results of delayed SCI suggested that deficits on MEP, wake-up test and histologic examination can indicate real SCI. However, evaluating blood flow may be important for verifying the cause of delayed SCI, which could also be related to ischemic injury. Prolonged distraction of cords may block spinal microcirculation without structural disruptions of axons, and neurotoxic material accumulation may result in SCI. ${ }^{17}$ In the reported literature, Kato et al. ${ }^{17}$ used LASER Doppler flowmetry to examine the effect of segmental artery interruption on spinal cord blood flow. In addition, Kawahara et al. ${ }^{18}$ studied the effects of acute spinal shortening on spinal cord blood flow with spinal cord angiography. However, to achieve parallel distraction of the vertebral column, we performed a compete osteotomy through the anterior column, which is prone to massive bleeding around the cord and significantly interferes with accurate microcirculation measurement. We abandoned spinal cord blood flow analysis after several trials, which may be a major limitation of our study. However, we were able to achieve a pure parallel distraction model, which may be the most similar model to iatrogenic human SCI. ${ }^{2,3}$ In addition, we performed the experiment in a large animal model, which minimizes biological differences, as the swine spinal column and neurophysiology are similar to those of humans. ${ }^{21,32}$ Therefore, the results of this study will be beneficial as a basis for additional neurophysiology studies and can be applied to future spinal cord surgical procedures.

In summary, we determined that delayed-type SCI with continuous spinal column distraction in swine was dependent on the distraction length and comparable to SVH. Understanding additional aspects of delayed SCI in large animals will be beneficial for treatment of SCI. The results of this study contribute to developing and managing SCI and provide information for future SCI investigations for human patients.

\section{DATA ARCHIVING}

There were no data to deposit.

\section{CONFLICT OF INTEREST}

The authors declare no conflict of interest.

\section{ACKNOWLEDGEMENTS}

This research was supported by the Basic Science Research Program through the National Research Foundation of Korea, funded by the Ministry of Education. This study was supported by a Korea University Grant (No. K1512681). However, no benefits in any form have been or will be received from a commercial party related directly or indirectly to the subject of this manuscript. According to the Ethical review committee statement, this study was performed under the approval of the Institutional Animal Care and Use Committee (IACUC). All experimental procedures, protocols and treatment of experimental animals were performed under the control of the IACUC. 
1 Kim YJ, Lenke LG, Cho SK, Bridwell KH, Sides B, Blanke K. Comparative analysis of pedicle screw versus hook instrumentation in posterior spinal fusion of adolescent idiopathic scoliosis. Spine 2004; 29: 2040-2048.

2 Lenke LG, Sides BA, Koester LA, Hensley M, Blanke KM. Vertebral column resection for the treatment of severe spinal deformity. Clin Orthop Relat Res 2010; 468: 687-699.

3 Suh SW, Modi HN, Yang J, Song HR, Jang KM. Posterior multilevel vertebral osteotomy for correction of severe and rigid neuromuscular scoliosis: a preliminary study. Spine 2009; 34: 1315-1320.

4 Hilibrand AS, Schwartz DM, Sethuraman V, Vaccaro AR, Albert TJ. Comparison of transcranial electric motor and somatosensory evoked potential monitoring during cervical spine surgery. J Bone Joint Surg Am 2004; 86-A: 1248-1253.

5 Langeloo DD, Journee HL, de Kleuver M, Grotenhuis JA. Criteria for transcranial electrical motor evoked potential monitoring during spinal deformity surgery A review and discussion of the literature. Neurophysiol Clin 2007; 37: 431-439.

6 Langeloo DD, Lelivelt A, Journee LH, Slappendel R, de Kleuver M. Transcrania electrical motor-evoked potential monitoring during surgery for spinal deformity: a study of 145 patients. Spine 2003; 28: 1043-1050.

7 Lyon R, Lieberman JA, Grabovac MT, Hu S. Strategies for managing decreased motor evoked potential signals while distracting the spine during correction of scoliosis. $J$ Neurosurg Anesthesiol 2004; 16: 167-170.

8 MacDonald DB, Al Zayed Z, Khoudeir I, Stigsby B. Monitoring scoliosis surgery with combined multiple pulse transcranial electric motor and cortical somatosensory-evoked potentials from the lower and upper extremities. Spine 2003; 28: 194-203.

9 Pelosi L, Lamb J, Grevitt M, Mehdian SM, Webb JK, Blumhardt LD. Combined monitoring of motor and somatosensory evoked potentials in orthopaedic spinal surgery. Clin Neurophysiol 2002; 113: 1082-1091.

10 Schwartz DM, Auerbach JD, Dormans JP, Flynn J, Drummond DS, Bowe JA et al. Neurophysiological detection of impending spinal cord injury during scoliosis surgery. $J$ Bone Joint Surg Am 2007; 89: 2440-2449.

11 Delank KS, Delank HW, Konig DP, Popken F, Furderer S, Eysel P. latrogenic paraplegia in spinal surgery. Arch Orthop Trauma Surg 2005; 125: 33-41.

12 MacEwen GD, Bunnell WP, Sriram K. Acute neurological complications in the treatment of scoliosis. A report of the Scoliosis Research Society. J Bone Joint Surg Am 1975; 57 404-408.

13 Pahys JM, Guille JT, D'Andrea LP, Samdani AF, Beck J, Betz RR. Neurologic injury in the surgical treatment of idiopathic scoliosis: guidelines for assessment and management. J Am Acad Orthop Surg 2009; 17: 426-434.

14 Choo AM, Liu J, Liu Z, Dvorak M, Tetzlaff W, Oxland TR. Modeling spinal cord contusion, dislocation, and distraction: characterization of vertebral clamps, injury severities, and node of Ranvier deformations. J Neurosci Methods 2009; 181: 6-17.

15 Dabney KW, Ehrenshteyn M, Agresta CA, Twiss JL, Stern G, Tice L et al. A mode of experimental spinal cord trauma based on computer-controlled intervertebral distraction: characterization of graded injury. Spine 2004; 29: 2357-2364.

16 Etz CD, Homann TM, Luehr M, Kari FA, Weisz DJ, Kleinman G et al. Spinal cord blood flow and ischemic injury after experimental sacrifice of thoracic and abdominal segmental arteries. Eur J Cardiothorac Surg 2008; 33: 1030-1038.
17 Kato S, Kawahara N, Tomita K, Murakami H, Demura S, Fujimaki Y. Effects on spinal cord blood flow and neurologic function secondary to interruption of bilateral segmenta arteries which supply the artery of Adamkiewicz: an experimental study using a dog model. Spine 2008; 33: 1533-1541.

18 Kawahara N, Tomita K, Kobayashi T, Abdel-Wanis ME, Murakami H, Akamaru T. Influence of acute shortening on the spinal cord: an experimental study. Spine 2005; 30: 613-620.

$19 \mathrm{Kim}$ SH, Chung JM. An experimental model for peripheral neuropathy produced by segmental spinal nerve ligation in the rat. Pain 1992; 50: 355-363.

20 Koozekanani SH, Vise WM, Hashemi RM, McGhee RB. Possible mechanisms for observed pathophysiological variability in experimental spinal cord injury by the method of Allen. J Neurosurg 1976; 44: 429-434.

21 Kwon BK, Oxland TR, Tetzlaff W. Animal models used in spinal cord regeneration research. Spine 2002; 27: 1504-1510.

22 Sandler AN, Tator $\mathrm{CH}$. Effect of acute spinal cord compression injury on regional spinal cord blood flow in primates. J Neurosurg 1976; 45: 660-676.

23 Zvara D, Zboyovski JM, Deal DD, Vernon JC, Colonna DM. Spinal cord blood flow after ischemic preconditioning in a rat model of spinal cord ischemia. Sci World J 2004; 4: 892-898.

24 Kaiser GM, Heuer MM, Fruhauf NR, Kuhne CA, Broelsch CE. General handling and anesthesia for experimental surgery in pigs. J Surg Res 2006; 130: 73-79.

25 Calancie B, Harris W, Broton JG, Alexeeva N, Green BA. "Threshold-level" multipulse transcranial electrical stimulation of motor cortex for intraoperative monitoring of spinal motor tracts: description of method and comparison to somatosensory evoked potential monitoring. J Neurosurg 1998; 88: 457-470.

26 Carlson GD, Gorden CD, Nakazowa S, Wada E, Warden K, LaManna JC. Perfusion-limited recovery of evoked potential function after spinal cord injury. Spine 2000; 25: 1218-1226.

27 Minahan RE, Sepkuty JP, Lesser RP, Sponseller PD, Kostuik JP. Anterior spinal cord injury with preserved neurogenic 'motor' evoked potentials. Clin Neurophysiol 2001; 112: $1442-1450$.

28 Yang JH, Suh SW, Modi HN, Ramani ET, Hong JY, Hwang JH et al. Effects of vertebral column distraction on transcranial electrical stimulation-motor evoked potential and histology of the spinal cord in a porcine model. J Bone Joint Surg Am 2013; 95: 835-842.

29 Modi HN, Suh SW, Hong JY, Yang JH. The effects of spinal cord injury induced by shortening on motor evoked potentials and spinal cord blood flow: an experimental study in Swine. J Bone Joint Surg Am 2011; 93: 1781-1789.

30 Lips J, de Haan P, Bouma GJ, Jacobs MJ, Kalkman CJ. Delayed detection of motor pathway dysfunction after selective reduction of thoracic spinal cord blood flow in pigs. J Thorac Cardiovasc Surg 2002; 123: 531-538.

31 Kozlowski P, Raj D, Liu J, Lam C, Yung AC, Tetzlaff W. Characterizing white matte damage in rat spinal cord with quantitative MRI and histology. J Neurotrauma 2008; 25: 653-676.

32 Dath R, Ebinesan AD, Porter KM, Miles AW. Anatomical measurements of porcine lumbar vertebrae. Clin Biomech 2007; 22: 607-613. 